\title{
Políticas Públicas e Direitos Humanos: uma releitura das relações raciais nas escolas brasileiras
}

\author{
Public Policies and Human Rights: a reinterpretation of race relations \\ in brazilian schools
}

http://dx.doi.org/10.5007/2178-4582.2013v47n1p16

Flavio Santiago

Universidade de Campinas, Campinas/SP, Brasil

Adriana Duarte de Souza Carvalho

Centro Universitário Claretiano de Batatais/SP, Brasil

O objetivo deste artigo é analisar as Diretrizes Curriculares Nacionais para a Educação das Relações Étnico-raciais e para o Ensino de História e Cultura Africana e Afrobrasileira, aprovada pelo parecer CNE 003/04 e sua Resolução 01/04 (Lei 10639/03), que alterou a Lei de Diretrizes e Base da Educação Nacional, tornando obrigatório o ensino de História e Cultura Afrobrasileira e Africana no currículo da educação básica. A metodologia é a análise documental das seguintes fontes legais: a Constituição de 1988 e seus anais; a LDBEN e as Diretrizes Curriculares para a Educação das Relações Étnico-Raciais. O trabalho aponta como esta política pública exigiu uma releitura das relações étnico-raciais e demandou um novo olhar do educador sobre a heterogeneidade para que os Direitos Humanos tivessem lugar na escola. Mostraremos que construção desse olhar não deve ser estabelecido dentro da lógica da negação dos direitos humanos, mas ser produzido através da recusa da homogeneização e da institucionalização de práticas inclusivas.

Palavras-chave: Direitos humanos - Políticas públicas - Relações étnico-raciais.
The purpose of this paper is to analyze the National Curriculum Guideline for Education on Ethnic-Racial Relations and the African and African-Brazilian History and Culture Teaching, approved by CNE 003/04 Bill and its Resolution 01/04 (10639/03 Act) which have changed the Guidelines and Basis for National Educational, turning the teaching of African and African-Brazilian History and Culture mandatory in the national curriculum for Basic Education. The methodology used was the documental analysis of the following legal acts: the Brazilian Constitution of 1998 and its following annals, the LDBEN and the National Curriculum Guidelines for the Ethnic-Racial Relations Education. This work shows how this public policy has demanded a new reading of ethnic-racial relations and how it has also imposed upon teachers a new look towards heterogeneity, so that Human Rights had a place inside schools. We will point out that the building of this new look should not be established by denying the logic of the Human Rights but rather by refusing homogenization as well as by the institutionalization of practices of inclusion.

Keywords: Human Rights - Public Policies - Ethnic-racial relations.

\section{Introdução}

A Constituição de 1934 é a primeira, no Brasil, a trazer dispositivos constitucionais veiculadores de direitos sociais à Educação. Em seu capítulo "Da Educação e da Cultura", a Constituição de 1934 determina que a União, os Estados e os Municípios e o Distrito Federal favoreçam o desenvolvimento 
da educação e da cultura e, em seu artigo 152, parágrafo único, afirma que compete aos Estados e ao Distrito Federal criar Conselhos de Educação. É fundamental enfatizar que a Carta Magna não previa a criação de tribunais aos quais os cidadãos pudessem se dirigir para exigir seus direitos à educação e à cultura, caso os mesmos não fossem cumpridos. Dessa maneira, a única forma de tornarem-se efetivos os direitos à Educação e à Cultura era através dos Poderes Executivo e Legislativo, por meio da criação de políticas públicas.

Historicamente, as instituições escolares e algumas pesquisas relativas a estas instituições vêm se isentando de reflexões sobre a educação e as relações étnico-raciais (CAVALLEIRO, 2005) e, principalmente, silenciam sobre a falta de efetividade dos direitos humanos na instituição escolar brasileira.

O silenciamento da escola e dos professores em relação aos direitos humanos, especificamente no que diz respeito a preconceitos contra determinados grupos étnico-raciais, é um dos elementos que contribuem para a construção de um olhar único, homogeneizado, muitas vezes voltado a um aspecto sociocultural europeu branco, pregando no sentido étnico-racial uma educação formal de embranquecimento, em contraposição à sociedade heterogênea que vai à escola.

Os sistemas educacionais, juntamente com os educadores manipulados, se pautam em ideologia racial eurocêntrica branca. Essa ideologia faz da branquitude o "sujeito universal e essencial", até normalizado. Este sujeito, associado a uma situação de privilégios que desacredita na presença da austeridade de sua posição, é incapaz de compreender a experiência do outro (ROSSATO; GESSER, 2001), tornando o padrão branco como sinônimo de pureza artística, nobreza estética, majestade moral e sabedoria científica.

Nas escolas, nos livros didáticos, nos meios de comunicação, faltam informações sobre a escravização dos africanos, sobre o tráfico e a travessia e sobre os interesses econômicos que tentaram transformar seres humanos em objetos. Faltam também informações sobre as iniciativas e lutas dos escravizados para pôr fim à escravidão, às desigualdades a que têm sido submetidos seus descendentes no que diz respeito à garantia de direitos, como educação, moradia, trabalho, salário digno, saúde, identidade, religiosidade.

O processo histórico mostra que diferentes ações foram se construindo aos longos dos séculos para combater o racismo presente na sociedade, procurando desconstruir o ideário colonial que estabelecia formas estereotipadas e preconceituosas de olhar o negro, sua cultura, e as relações que ele estabelece com o mundo. A luta também era por conquistas no plano legal, que institucionalizassem direito civis e sociais que foram negados à população negra.

A educação sempre foi pensada pela população negra brasileira como um meio de resistência e ascensão social; através dela os/as negros/as poderiam 'melhorar de vida'. Organizações negras surgem para defender e exigir uma educação para esta população. Vale ressaltar que a população negra escravizada foi impedida por lei de estudar, podendo, posteriormente, frequentar apenas escolas noturnas. Domingues (2007) afirma que, no início do século $\mathrm{XX}$, surgiu no Brasil, um movimento político ideológico denominado Im- 
prensa Negra que trazia, nos seus jornais, denúncias de racismo contra os negros em espaços públicos, de lazer e em contratações de emprego. Por meio de jornais, a Imprensa Negra se configura como movimento em que entidades negras articulam um caminho educativo. Em seus periódicos, é possível verificar padrões de conduta que deveriam ser seguidos pela comunidade negra para se tornarem "cidadãos de bem", sendo a educação uma passagem mais rápida e segura para uma condição de vida melhor. Neste momento, as entidades promulgam a ideia do negro se educar.

Ao longo das décadas de 1940 a 1960, os movimentos sociais negros continuam a se articular pautados pela educação. Segundo dados do Ministério da Educação e da Cultura (BRASIL, 2006), destacam-se as atuações do Teatro Experimental do Negro (TEN) e do Comitê Afro-brasileiro, fundado em 1945. Nos anos de 1945-46, foram realizados dois encontros da Convenção do Negro Brasileiro que propunham ações políticas no sentido de resgatar a memória africana e afro-brasileira, a liberdade de culto das religiões de matriz africana e a participação do negro como sujeitos de sua história. Nas décadas de 1970-80, entidades de movimentos negros, que ressignificam ${ }^{1} \mathrm{o}$ conceito de raça e do termo raça negra, passam a significar uma reivindicação, uma busca por uma ascendência africana comum, por um pertencimento cultural, isto é, aquilo que Hall chama de "experiência negra na diáspora'2 ou "uma experiência histórica [comum] do povo negro na diáspora" (HALL, 2005, p.343).

Valores culturais e aspectos de africanidades são recriados, uma estética negra (HALL, 2005) é apropriada às experiências dos povos na diáspora negra, o conceito de raça é recriado. A cor - a "diferença do objeto da discriminação", o "signo cultural/político de inferioridade ou degeneração, a pele como sua identidade natural" (BHABHA, 2005, p.123) - se processa e é reinventada, recolocada. Em um primeiro momento, as ações dos movimentos negros se pautaram na educação como ascensão social e resistência pessoal; num segundo momento, a educação é vista como obrigação do Estado e, a partir da denúncia da discriminação racial e da falta de preparo dos profissionais da educação para tratar das questões raciais em sala de aula, medidas institucionais são efetuadas para a inclusão do sujeito negro no currículo e para o combate efetivo da discriminação racial na escola.

Em face das ações do movimento negro para uma educação que contemplasse as diferenças raciais, destacam-se as atuações políticas para inserção da história do negro nos currículos oficiais. Nas décadas de 1970-80, a tônica foi a inclusão nos currículos oficiais de conteúdos que valorizassem a cultura negra e aumentassem a autoestima e a construção de uma identidade positiva nas crianças negras, os chamados estudos africanos (PINTO, 1993). Nota-

\footnotetext{
1 O sentido de ressignificar é dar novo sentido, uma busca por uma nova simbologia que dá caráter valorativo positivo, no caso, a história da África e da população negra na diáspora, aqui entendida como experiência e situações comuns.

2 Diáspora significa saída forcada de um grupo ou povo por motivos políticos, religiosos ou ideológicos. Neste caso, a diáspora dos povos negros para as Américas pelo regime escravista.
} 
se, a partir da década de 1990, ações em âmbito local com revisões de livros didáticos em que os negros são apontados de forma estereotipada, como servis, sem atitude e de forma negativa. Ações localizadas de municípios, de acordo com Santos (2005), passaram a atender algumas reivindicações dos movimentos negros. Em linhas gerais, algumas leis em âmbito municipal garantiram o direito à educação, o respeito às contribuições de matriz afro-brasileira, como as religiões e o combate às formas de discriminação e preconceito. Dentre algumas leis, destacam-se as que incluem o ensino de História dos Negros no Brasil e do Continente Africano (Ibid., p.29). Nessas propostas nota-se que o termo utilizado é 'Raça Negra' para se referir à história Afro-brasileira e às contribuições dos negros/as no Brasil.

$\mathrm{Na}$ esfera federal, as ações são focadas na inserção dos conteúdos relativos à abordagem das diferenças em educação, nas propostas dos Temas Transversais. Os PCNs (Parâmetros Curriculares Nacionais), entre outras propostas, apontam as relações de raça, gênero, contribuição das culturas diversas ao Brasil. A forma como a presença do(a) negro(a) é vista e retratada nos livros didáticos - um dos materiais mais utilizados na pedagogia dos(as) professores(as) - é alvo de críticas por parte do movimento negro. Os livros, em geral, "[...] omitem ou apresentam de uma [forma] simplificada e falseada o cotidiano, as experiências e o processo histórico-cultural de diversos segmentos sociais" (SILVA, 2005, p.23). E, quando não são omitidos, estes conteúdos são mostrados de forma estereotipada. As propostas, no entanto, orientam que a inserção dos conteúdos aconteça de forma transversal, o que, em certa medida, não se compromete com um projeto efetivo de mudança da matriz curricular.

Dentre as últimas medidas governamentais mais significativas, destaca-se a Lei 10.639/2003, que altera a LDB e institucionaliza a obrigatoriedade do ensino de História da África e Cultura Afro-Brasileira e Africana nos estabelecimentos de ensino públicos e privados brasileiros. Em suma, esta medida é produto de reivindicações históricas do movimento negro brasileiro, de profissionais da educação e da população negra. A institucionalização desta Lei tem trazido algumas situações-problema para professores(as) e alunos(as). O Parecer 003/2004, que regulamenta as alterações da LDB instituindo as Diretrizes Curriculares para a Educação das Relações Étnico-Raciais e para o ensino de História e Cultura Afro-Brasileira e Africana vem auxiliar para que estes conteúdos sejam efetivados, mas esta medida tem colocado um dilema aos profissionais de educação: conhece-se pouco a África e a história dos povos negros.

\section{Objetivos}

Diante desse quadro, queremos apontar como milhares de crianças vivenciam, diariamente, práticas racistas e discriminatórias nas diversas instituições escolares, autênticas violações de direitos humanos, que contribuem para que diferenças fenotípicas sejam entendidas como 
pressupostos naturais das desigualdades sociais. Queremos, ao mesmo tempo, apontar como políticas públicas podem ser capazes de mudar esse quadro.

Para Cavalleiro (2005), o racismo cotidiano não só impede o florescimento do potencial intelectual de milhares de mentes brilhantes nas escolas brasileiras, como também nos embrutece ao longo de nossas vidas, impedindo que sejamos seres realmente livres. O racismo e as práticas discriminatórias no interior das instituições escolares tornam-se elementos de coerção e neutralização de diferentes vozes, entre elas a negra, tendo como objetivo central construir uma única perspectiva de mundo, embebida em uma visão eurocêntrica branca, desvalorizando e ignorando outras: a indígena, a africana e a asiática.

Entretanto, esta forma de educar, pautada na desvalorização do outro e na negação da diferença, não é concebida por todos os homens e mulheres do mundo, existindo, paralelamente, uma luta constante para que se desconstruam esses processos de ensino e aprendizagem e para que se (re)construam novas formas de ensinar e aprender no cotidiano escolar. No nosso entendimento, o papel do docente é fundamental para pensar a revalorização da alteridade e para a inclusão da diferença, preservando os direitos humanos na instituição escolar.

A luta do Movimento Negro, ao longo do século XX, pela construção da educação das relações étnico-raciais e por mudanças na educação escolar, pode ser tomada como um exemplo de reivindicações de direitos humanos. O Movimento Negro apresenta novas propostas para se ensinar e aprender, desarticulando a visão unitária (eurocêntrica) estabelecida dentro dos currículos, e possibilitando a construção do respeito e valorização de todas as raízes culturais que constituem a nação brasileira. Dessa maneira, queremos apontar como as instituições de ensino, juntamente com os professores, podem incorporar esses saberes, de forma a aplicar os direitos humanos nos currículos escolares.

\section{A Lei 10639/2003}

A lei 10639/2003 reflete sobre como a sociedade organizada é capaz de modificar o ordenamento jurídico, pressionando os atores políticos representativos a alterarem o status quo legislativo (TSEBELLIS, 2009). Essa luta não é mera discussão partidária ou modismo educacional. Antes, é uma postura ética daqueles que se dispõem a trabalhar para o encontro das diferenças existentes no interior das escolas (GOMES, 2006). Além disso, é uma luta por uma legislação que inclua currículos por meio do quais a diversidade seja constante nas vozes de nossos educadores, não tratando somente de oferecer aprendizagem a negros indígenas ou marginalizados, mas sim a todos aqueles que estejam dispostos a trocar conhecimentos (BRASIL, 2004a ).

As ações e reivindicações do Movimento Negro têm o propósito de promover oportunidades de educação que permitam a criação de condições do exercício pleno da cidadania (GONÇALVES; SILVA, 2000). 
Cidadania que requer o conhecimento, o respeito e a valorização de todas as raízes culturais que constituem a nação (MORAIS; OLIVEIRA; SILVA, 2008). Segundo Rodrigues (2006), a luta do Movimento Negro por mudanças nas formas de ensinar e aprender dentro das escolas acontece a partir da compreensão da educação como a base sobre a qual se estrutura a forma de pensar e agir de um povo. Esta compreensão foi se construindo a partir dos anos 1930, quando a educação escolar passou a ser compreendida como sinônimo de instrução, o que proporcionaria fornecer instrumentos para a promoção das demandas da população negra e contribuir para o combate às desigualdades sociais e raciais (CAVALLEIRO, 2005).

Ao reivindicar o reconhecimento da cultura, da política e da história da população negra para os sistemas de ensino, o Movimento Negro faz críticas ao currículo escolar e à profissão docente, entendidos como atividades políticas que podem ser vistas em dois sentidos: em uma ação e em um efeito, não se restringindo somente a idéias e abstrações, mas a experiências e práticas concretas construídas por sujeitos (GOMES, 2006). Como resultado dessa luta, a aprovação da Lei 10639/2003, que alterou a Lei de Diretrizes e Bases (LDB) - 9394/1996 nos artigos 26-A e 79-B, tornou obrigatório o ensino de História e Cultura Afro-brasileira e Africana no currículo oficial da educação básica, incluindo o dia 20 de novembro como "Dia Nacional da Consciência Negra" no calendário escolar .

O objetivo central dessa lei é corrigir desigualdades educacionais e garantir o reconhecimento do valor da história e da cultura dos diferentes povos que constituem a nação brasileira (MORAIS; OLIVEIRA; SILVA, 2008). Com ela, pretende-se abandonar o ocultamento da diversidade no Brasil que tem cultivado, entre indígenas, negros e empobrecidos, o sentido de não pertencimento à sociedade, ocasionando uma distorção das relações étnico-raciais. Dessa forma, acaba-se pregando uma democracia racial em uma sociedade em que não se vê as diferenças (SILVA, 2007).

De fato, a Constituição de 1988 - intitulada por muitos de "Constituição Cidadã" - vem dizer que a diversidade brasileira e todos aqueles excluídos da sociedade devem ter acesso a direitos humanos, incluindo, evidentemente, o ensino de História e Cultura Afro-brasileira e Africana no currículo oficial da educação. A democracia se assenta em dois princípios básicos: a liberdade e a igualdade. Dessa forma, a lei 10639/2003 busca a concretização da igualdade.

A literatura (ARANTES; COUTO 2008), contudo, apresenta severas críticas à constitucionalização de direitos humanos empreendida pela Assembleia Constituinte de 1986-88. O problema levantado é que a Constituição de 1988 não prevê condições reais para a concretização plena desses direitos, o que acaba transformando-os em meras promessas não cumpridas pelo Estado ou, então, em figuras de retórica sem vigor coercitivo (ATRIA, 2004).

Os direitos humanos, constitucionalizados em 1988, não teriam um caráter jurídico, limitando-se a ser apenas um simples conjunto de decisões políticas, sem nenhum caráter coercitivo. A Constituição não teria determinado uma proteção juridicamente exigível aos direitos sociais, pois estes dependem 
de mecanismos institucionais que um juiz não pode, pelo tipo de cargo que ocupa, criar. Em outras palavras, a efetivação dos direitos sociais depende de decisões políticas, não jurídicas, ou seja, está sujeita à implementação de políticas públicas. Os direitos sociais, portanto, não seriam de fato autênticos direitos, mas apenas princípios dirigentes da política social e econômica do Estado ou, então, meros programas de ação para os governantes.

Entre a promulgação da Constituição de 1988 e a aprovação da Lei 10639/03, ocorreram diferentes movimentos de luta política que visaram legitimar os direitos da população negra. Alguns dos marcos são: a Marcha de Zumbi dos Palmares (1995), os Seminários Regionais Preparatórios para Conferencia Mundial Contra o Racismo Discriminação Racial; Xenofobia e intolerância Correlata; a III Conferência Mundial das Nações Unidas Contra o Racismo, Discriminação Racial, Xenofobia e intolerância Correlata, realizada pela ONU em Durban, na África do Sul, no ano de 2001. Segundo Silva,

\footnotetext{
Do ponto de vista legislativo, a Lei é de autoria da Deputada Esther Grossi e do Deputado Ben-Hur Ferreira, ambos do Partido dos Trabalhadores e foi apresentada na Câmara dos Deputados como Projeto de Lei no 259, em 11 de março de 1999. Tal projeto é aprovado e remetido ao Senado no dia 05 de abril de 2002, sendo seu secionamento uma das primeiras iniciativas do governo do presidente Luiz Inácio Lula da Silva, em 09 de janeiro de 2003. (SILVA, 2009, p.11)
}

No processo de regulamentação da lei 10639/2003, ocorreram durante o ano de 2008 seis encontros regionais e um encontro nacional que serviram de base para a construção do Plano Nacional de Implementação das Diretrizes Curriculares para a Educação das Relações Étnico-Raciais e para o Ensino de História e Cultura Afro-brasileira e Africana que trataremos a seguir.

\section{Políticas públicas para implementação de direitos humanos na escola}

A fim de estabelecer o cumprimento da Lei 10.639/2003, o Conselho Nacional de Educação se manifesta, estabelecendo as Diretrizes Curriculares Nacionais para a Educação das Relações Étnico-raciais e para o Ensino de História e Cultura Africana e Afro-Brasileira, por meio da aprovação do parecer CNE 003/2004 e da Resolução 01/2004. Essa legislação é um modelo de política pública, implementada para a modificação do processo de exclusão promovido pelo nosso sistema educacional e seus educadores, por meio da negação dos direitos humanos.

Como destaca o parecer CNE 003/2004, as Diretrizes Curriculares Nacionais para a Educação das Relações Étnico-raciais e para o Ensino de História e Cultura Africana e Afro-Brasileira são uma "política curricular fundada em dimensões históricas, culturais, sociais e antropológicas oriundas da realidade 
brasileira, e busca combater o racismo e as discriminações que atingem particularmente os negros" (BRASIL, 2004b, p. 10).

A educação das relações étnico-raciais se fundamenta como política pública de reconhecimento que "requer adoções de políticas educacionais que valorizem a diversidade, a fim de superar as desigualdades étnico-raciais presentes na sociedade" (Ibid., p. 11), bem como de reparação para a educação dos negros, "buscando a valorização do patrimônio histórico-cultural afro-brasileiro, de aquisição das competências e dos conhecimentos tidos como indispensáveis para continuidade nos estudos" (Ibid.). Isso implica, necessariamente, reformas educacionais e o reposicionamento de nossos educadores.

O conjunto de ações voltadas para o reconhecimento e reparação pode ser entendido como uma política de ações afirmativas que visa corrigir desigualdades raciais e sociais, "orientada para oferecer tratamento diferenciado com vista a corrigir desvantagens e marginalizações criadas e mantidas por estruturas sociais excludentes e discriminatórias" (BRASIL, 2004, p. 12).

As políticas públicas voltadas para o reconhecimento de grupos e populações historicamente excluídas devem fornecer as bases de uma educação que contemple as várias culturas e que fortaleça suas identidades, por meio da percepção histórica. O que contam sobre a história de povos e culturas na sala de aula sobre o que se é e como se é faz parte de uma constituição de identidades, um "[...] processo de construção de significado com base em atributos culturais inter-relacionados, o(s) qual (ais) prevalecem $(\mathrm{m})$ sobre outras formas de significado (CASTELLS, 2005, p.22). A ação didática dos(as) profissionais da educação também influi no desenvolvimento dos(as) alunos(as). Os estereótipos sobre o negro e sua história - sempre ligada ao escravismo - criam efeitos negativos na visão que negros(as) e não- negros(as) têm de África e de seus descendentes.

Como se vê, é complexa, mas não pode ser tomada como impossível, a tarefa de educar para/na educação das relações étnico-raciais, pois construí-la é proporcionar a "edificação" de um olhar para além do único, é possibilitar a abertura para diferentes encontros ao movimento do pensamento. A escola, a partir dessa perspectiva, deixa de sancionar, como correto, o hegemônico e o transcendental para possibilitar linhas de fugas para diferentes percepções de mundo e construções dos conhecimentos (PELBART, 2005).

Ao ressaltarmos a necessidade de rompimento com esse processo não estamos advogando a favor de uma inversão binária da história da humanidade, mas sim tentando construir "outros modos", que não se pautem por um olhar único que visa colonizar, de modo catequético, todos os sujeitos. $\mathrm{O}$ que pretendemos propor é a construção de uma pedagogia da infância que se arquiteta no encontro da diferença, desarticulando as amarras do hegemônico, do correto, do verdadeiro, do único. Isto possibilita emergir o pensamento africano, não a partir de estereótipos construídos socialmente, mas sim da maneira própria dos negros se colocarem no mundo, ao receber o mundo em si. Trata-se de trazer procedimentos e pensamentos que orientem a produção de 
conhecimentos oriundos de valores e princípios próprios da matriz africana, apresentando não somente uma mentalidade "europeia branca" para entender os fenômenos, rompendo com a compreensão de homogeneidade do conhecimento (SILVA, 1995).

Neste sentido, como apresenta Silva (2007), é esperado que o jeito de ser, viver e pensar de diferentes grupos étnico-raciais sejam respeitados e incluídos na construção das pedagogias, o que não significa que se descuide ou se fragilize a aprendizagem de conhecimentos específicos das ciências e da cultura branca. Ao contrário, a meta é completar tais aprendizagens, promovendo, juntamente com o estudo das contribuições europeias para a humanidade, as africanas, as indígenas, entre outras.

A transformação do pensamento dos negros em conteúdos programáticos do currículo e sua transmissão por nossos professores promovem a remoção de um passado construído sobre práticas de dominação e de exclusão, e criase a força de emancipação, entendida como instrumento para a construção de uma identidade negra e de um pertencimento étnico-racial (BARBOSA; SILVA, 1997). Enegrecer a educação com pensamento de base teórica africana é possibilitar e garantir o respeito e a valorização de um povo cuja ancestralidade foi negada e conduzida a um status de (sub)cultura por um sistema de poder ligado à exploração e exclusão (SILVA, 2007).

Não se trata de reduzir o ensino a questões estruturais da sociedade ou a manifestações culturais pontuais, tais como: canção, comida típicas, indumentárias, mas sim de incorporar ao ensino o conjunto de valores culturais do mundo africano, tal como se exprime na vida, nas instituições e nas obras dos negros e, dessa forma, recuperar os direitos humanos perdidos na história em decorrência do racismo colonial.

Os direitos humanos, por se pretenderem universais, devem ser aplicados isonomicamente a todo ser humano, a sujeitos igualmente portadores de direitos. Tais direitos são inalienáveis, porque não podem ser hierarquizados ou sobrepostos entre si; e são indivisíveis, porque os direitos políticos, econômicos, sociais e culturais estão inter-relacionados, são inseparáveis, ou seja, eles não podem ser praticados isoladamente. Se aplicados a todos os sujeitos, os direitos humanos deveriam ultrapassar as diferenças regionais, sociais, políticas e culturais entre os cidadãos em cada um Estados que assinaram as convenções internacionais.

O Estado brasileiro, como Estado-membro da ONU, assinou a Declaração Universal dos Diretos Humanos em 10 dezembro de 1948. A adesão do Estado brasileiro aos principais instrumentos internacionais de proteção e defesa aos direitos humanos da ONU e, principalmente, à incorporação de alguns princípios da Declaração à Constituição Federal de 1988 demonstra que o Estado brasileiro está comprometido com o combate à violação dos direitos humanos (PIOVESAN, 2005; SANTOS; 2004; COMPARATO, 1999). Essa adesão é um dos elementos importantes para a viabilização de políticas públicas de promoção da igualdade racial e de combate ao racismo, em todos os âmbitos, 
especialmente, no campo da educação tendo em vista o papel de formação da educação que os sistemas de ensino assumem.

O Brasil também é signatário da Convenção $n^{0} 111$ sobre Discriminação em Emprego e Profissão da Organização Internacional do Trabalho/OIT. Ambas foram promulgadas pelas Nações Unidas e, em 1968, ratificadas pelo Brasil. Elas asseguram a igualdade de condições de direito da para a população negra, condenam a discriminação racial e preveem que os Estados-membros adotem medidas compensatórias para assegurar os direitos fundamentais dos grupos sociais discriminados por meio da promoção da igualdade racial.

Desse modo, ao adotar essas Convenções, o Estado brasileiro comprometeu-se a implementar políticas públicas de combate ao racismo e às diferentes formas de discriminação, assim como a promover a igualdade étnico-racial para os grupos discriminados. Ao incluir a experiência de luta contra o racismo, as demandas por reconhecimento e afirmar que os direitos dos negros são direitos humanos, o Estado brasileiro incluiu na sua agenda políticas direcionadas à promoção da igualdade racial e se tornou responsável pelos direitos de todos os cidadãos que sofrem racismo e violações de direitos.

Para alguns pesquisadores e estudiosos da questão étnico-racial, o fato de o Brasil ser signatário desses instrumentos internacionais não significou, no entanto, a sua efetiva implementação pelo Estado brasileiro. Silva Júnior (2001, p.14), afirma que "a inscrição do princípio da não-discriminação e as reiteradas declarações de igualdade têm sido insuficientes para estancar a reprodução de práticas discriminatórias na sociedade brasileira". Assim sendo, a incorporação de instrumentos e mecanismos internacionais de direitos humanos na Constituição Federal Brasileira de 1988, quando não articulados ao sistema jurídico, não são suficientes para garantir a sua efetividade na prática e sua implementação pelas políticas públicas de Estado.

Cabe também mencionar que a Conferência Mundial de Direitos Humanos, realizada em Viena, em 1993, teve como destaque o avanço e a consolidação da Declaração Universal dos Direitos Humanos. A Conferência os reafirmou como universais, inalienáveis, indivisíveis e interdependentes. Frente à emergência das novas configurações sociais e culturais e das lutas políticas dos diferentes grupos sociais por reconhecimento à identidade e à diferença, a Conferência destacou a importância da identidade política dos sujeitos específicos - por raça e etnia, religião, sexo, entre outros. Ela atribuiu a todos os Estados participantes o compromisso de serem agentes de promoção da igualdade e de implementarem a legislação e políticas antidiscriminatórias (BARSTED; HERMANN, 2001), de modo a eliminar todas as formas de racismo, discriminação racial, xenofobia e intolerância correlata.

Neste sentido, a educação das relações étnico-raciais torna-se uma política pública a favor dos direitos humanos, cujo objetivo é desfazer mentalidades racistas e discriminadoras seculares. Como pontua Silvério, 
[...] esse projeto político de educação procura superar o etnocentrismo europeu, para a desalienação dos processos pedagógicos, com fins de construir pedagogias que desvendem os mecanismos racistas e discriminatórios com o objetivo de reeducar as relações étnico-raciais (SILVÉRIO, 2002, p. 90)

Como apresentado no Parecer CNE/CP 003/2004, a educação das relações étnico-raciais deve promover oportunidades que ponham em comunicação diferentes sistemas simbólicos e estruturas conceituais, buscando formas de convivência respeitosas, construindo um projeto de sociedade em que todos sejam encorajados a expor, defender sua especificidade étnico-racial e a buscar garantias para que ninguém deixe de fazê-lo. A exigência por reconhecimento clama por uma revisão teórica, mostrando-nos a centralidade de algumas categorias como etnia, raça, gênero, sexualidade, cultura e como essas categorias tencionam a retórica da consagrada democracia racial e tradição universalista, obrigando países, como por exemplo o Brasil, a rever seu modelo singular de pluralismo cultural. Ao introduzir o uso de particularidades grupais e ao dar ênfase positiva à construção de identidades étnico-raciais, nega-se a visão otimista e homogênea do processo de integração e consolidação da ideia de "povo brasileiro", viabilizado pelo silenciamento e pela assimilação das diferenças.

Caso esse processo de construção multirreferencial seja negado, os negros e negras passam a ser interpretados e conceituados por meio de linguagens e de signos distintos do seu pertencimento cultural. Como aponta Fanon (2008), os negros passam a ter que construir o seu referencial com base nos olhares eurocêntricos:

Eu tinha o olhar do homem branco nos olhos. Um peso desconhecido me oprimia. No mundo branco o homem de cor encontra dificuldades no desenvolvimento de seu esquema corporal... Eu era atacado por tantãs, canibalismo, deficiência intelectual, fetichismo, deficiências raciais... Transportei-me para bem longe de minha própria presença... O que mais me restava senão uma amputação, uma excisão, uma hemorragia que me manchava todo o corpo de sangue negro (FANON, 2008, p.110112).

As crianças negras, dentro desse contexto, são cotidianamente violentadas e destituídas de sua ancestralidade, criando a necessidade de processos reiterativos que apaguem o seu pertencimento étnico-racial e que as tornem sujeitos desejantes de uma cultura dominante imposta pela força colonial. A imagem de integração harmoniosa perde totalmente o sentido dentro deste contexto, sendo explodida em prol do reconhecimento das diferenças étnico-raciais realmente existentes no país, contrastando radicalmente com o apagamento identitário contido na afirmação de uma identidade nacional mestiça retratada, por exemplo, na obra de Freyre (1933). 
Podemos notar, no Brasil, especialmente a partir da década de 1970, um processo de reorganização dos movimentos sociais, principalmente dos movimentos negro, feminista e indígena que, após vinte e um anos de ditadura militar, se reorganizaram para participar e influir no processo de discussão e elaboração da Constituição Federal de 1988. As reivindicações por reconhecimento político e respeito aos particularismos étnico-raciais e culturais apresentadas na Assembleia Nacional Constituinte e em ocasiões posteriores trazem duas implicações - teórica e política - que no escopo deste trabalho são analisadas em separado apenas para fins analíticos.

A primeira implicação corresponde à preocupação de distintas perspectivas teóricas que se ocupam dessa discussão, de mudanças da matriz de políticas públicas e de como compatibilizar as exigências de respeito à diferença reivindicadas por grupos sociais sem restringir-se ao relativismo cultural. Ao mesmo tempo, essas distintas perspectivas teóricas atribuem diferentes significados e possibilidades à ideia de diversidade.

A segunda implicação, concomitante à primeira mas nem por isso menos contraditória, é a irrupção dessa temática na arena política. Ainda que incipiente, vemos surgir, a partir da década de 1990, um número expressivo de programas e iniciativas do Governo Federal que reafirmam o caráter pluricultural da sociedade brasileira e a necessidade de respeito à diversidade. Levantamentos iniciais indicam que essas ações concentram-se nos ministérios da Cultura, da Saúde e, sobretudo, no da Educação, o que reafirma a centralidade da educação, enquanto processo - e da escola, como instituição social - no enquadramento e/ou mediação dos dilemas colocados à sociedade brasileira nesse início de século. Campbell (2002) assevera esta centralidade ao afirmar que :

\begin{abstract}
[...] para que a educação não corra o risco de condenar a si própria à irrelevância, ela terá de contribuir para a resolução daquele que parece ser o mais premente dos desafios enfrentados pela humanidade - alcançar a unidade e, simultaneamente, reter, respeitar, valorizar e incentivar a diversidade (CAMPBELL, 2002, p. 21).
\end{abstract}

O Plano Nacional de Educação em Direitos Humanos é outra importante política pública, e estabelece uma ponte com a sociedade civil no que diz respeito à conquista e efetivação de direitos humanos. A elaboração do Plano começou em 2003 e foi concluída em 2006, apontando a necessidade do empoderamento de grupos vulneráveis da sociedade civil, entre eles os negros. Não há dúvidas de que a obrigatoriedade do ensino da história e da cultura negra é fundamental para o empoderamento dos mesmos, pois aponta para a valorização dessa cultura na construção do Brasil.

Além disso, o PNEDH (2007, p.24) tem como objetivo fundamental “(...) fomentar o entendimento, a tolerância, a igualdade de gênero e a amizade entre as nações, os povos indígenas e grupos raciais, nacionais, étnicos, re- 
ligiosos e linguísticos". Para concretizar esse objetivo, o PNEDH propõe desenvolvimentos de estratégias de ações afirmativas. Como política pública, o PNEDH mostra que o princípio democrático da igualdade está em processo de efetivação por meio da educação.

\section{Conclusão}

Em 9 de Janeiro de 2013, a Lei 10639/03 comemorou dez anos. Entre inúmeros avanços decorrentes dessa lei, podemos perceber que nossos atores políticos reconhecem que a educação é o lugar por excelência de transformação das relações sociais, em todos os âmbitos, inclusive o das relações étnico-raciais. Aponta, finalmente, que essa transformação deve ultrapassar o âmbito do político e atingir o âmbito da cultura, por meio dos professores em sala de aula. Esse é, de fato, o maior desafio da lei: que ela ultrapasse a âmbito político-legislativo e se transforme em ações concretas em sala de aula, capazes de modificar o paradigma da discriminação. Como destaca Gusmão (1999, p.45), a escola como "espaço de transformação ao encontro das diferenças étnico-raciais deve questionar a validade e a legitimidade do modelo que é tomado como único no interior da cultura da qual somos herdeiro."

É importante destacar ainda, como ressalta Silva (2009), que não se trata de leviana rejeição a pensamentos alheios ao mundos africanos, tampouco de mera mudança de pontos de vista ou de referências teóricas usualmente empregadas, mas de premência por uma nova mentalidade, imprescindível para que se compreendam ou se expliquem os processos educativos vivenciados pelos negros. O propósito é romper com significados produzidos em perspectivas eurocêntricas que têm sido adversas a africanos e afrodescendentes, por instigá-los a se submeter a interesses e pensamentos que se pretendem universais.

A educação das relações étnico-raciais abre pista para se compreender o jogo das relações de poder e questiona sobre quem pode e produz conhecimento; sobre quem tem podido influir nas decisões dos percursos a serem seguidos pela sociedade. Questões como essas não podem mais ser compreendidas e enquadradas nos conceitos produzidos a partir do modelo eurocêntrico, sem sofrer um profundo e constante questionamento.

Desse modo, as Diretrizes Curriculares Nacionais para a Educação das Relações Étnico-raciais e para o Ensino de História e Cultura Afro-Brasileira e Africana ${ }^{3}$, ao destacarem a importância da educação das relações étnico-raciais, afirmam que ela "impõe aprendizagens entre negros e brancos, trocas de

3 A Lei n ${ }^{\circ} 10.639 / 03$, aprovada em 9 de janeiro de 2003, altera a Lei 9.394/96 de Diretrizes e Bases da Educação Nacional (LDB) e torna obrigatório o ensino de História e Cultura Afro-Brasileira e Africana no currículo oficial do ensino médio e fundamental brasileiro. A Lei 11.645, aprovada em 10 de março de 2008, altera o art. 26-A e introduz pela Lei 10.639/2003 no currículo oficial da rede de ensino, pública e privada, a obrigatoriedade da temática "História e Cultura Afro-Brasileira e Indígena". 
conhecimento, quebra de desconfianças, projeto conjunto para a construção de uma sociedade justa, igual, equânime" (BRASIL, 2004, p.14).

Para obter êxito, a escola e seus professores não podem improvisar. Temos que desfazer mentalidades racistas, superando o etnocentrismo europeu, reestruturando as relações étnico-raciais e sociais (BRASIL, 2004). A educação para/das relações étnico-raciais rompe com a idéia de sistema de ensino pautado no único. Contudo,

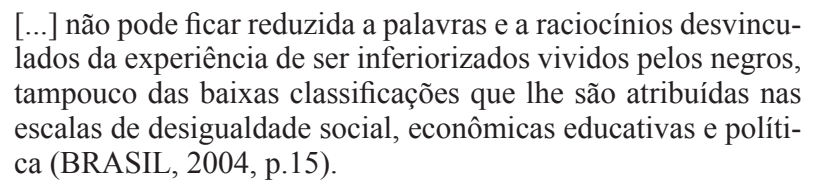

É necessário também que os professores(as) tenham um comprometimento político a favor da afirmação das diferenças, desconstruindo, em sua prática cotidiana, concepções homogeneizadas como, por exemplo, a do padrão considerado ideal de homem, com determinadas características associadas a uma estética eurocêntrica supervalorizada, em detrimento de quaisquer estéticas que não se assemelhem a ela. É importante destacar que não se trata de acrescentar conteúdos em datas específicas criando "momentos da diversidade", mas de trabalhar os processos educativos a partir da perspectiva da diferença, mostrando que existem diferentes visões de mundo, distintas realidades socioculturais e históricas.

Educar deve se tornar um ato político (FREIRE, 1978), em que discriminações, pensamentos racistas e quaisquer formas de desumanização dos sujeitos envolvidos não sejam percebidas como algo natural, corriqueiro e passageiro. Deve também resgatar direitos humanos negados por séculos de exclusão. O ensino teria por finalidade a ampliação das percepções de mundo, de sujeitos e de realidades socioculturais, construindo um ambiente em que o outro não seria mais um elemento, mas sim peça fundamental para construção da ação educativa.

Educar nas e para as relações étnico-raciais é propiciar a criação de espaço de fortalecimento do pertencimento étnico-racial de negros e também dos não-negros, dando subsídios para lutar contra desigualdades e opressões e promovendo o reconhecimento da história e cultura de todos os povos.

\section{Referências bibliográficas}

ABRAMOWICZ. Anete; OLIVEIRA, Fabiana de. A escola e a construção da identidade na diversidade. In: ABRAMOWICZ, Anete; SILVEIRO, Valter Roberto. (Org.) Afirmando Diferenças: Montando o quebra-cabeça da diversidade na escola. Campinas: Papirus, 2005. p. 41-64.

ARANTES, Rogério Bastos; COUTO, Cláudio Gonçalves. A Constituição sem Fim. In: PRAÇA, Sérgio e DINIZ, Simone (Orgs.). Vinte Anos de Constituição. São Paulo: Paulus, 2008. 
ATRIA, Fernando. “Existen derechos sociales?” Discusiones. n. 4, 2004. Disponível em: $<$ http://www.cervantesvirtual.com/partes/328330/discusiones--0> Acesso em: 25 abr. 2012.

BARSTED, Leila Linhares; HERMANN, Jaqueline. Mulheres negras e indígenas: a lei e a realidade. In: BARSTED, Leila L.; HERMANN, Jacqueline (Orgs.) As mulheres e a legislação contra o racismo. Rio de Janeiro: CEPIA, 2001.

BHABHA, Homi K. O local da cultura. Belo Horizonte: Editora UFMG, 2001.

BRASIL. (Presidência da República). Constituição da República Federativa do Brasil - 1988 Brasília, DF, 5 out. 1988. Disponível em: <http://www.planalto.gov.br/ccivil_03/Constituicao/ Constituicao.htm> Acesso em: 24 abr. 2011.

.(Conselho Nacional de Educação) Parecer CNE/CP 3/2004. Diretrizes Curriculares Nacionais para a Educação das Relações Étnico-Raciais e para o Ensino de História e cultura Afro-Brasileira e Africana. Diário Oficial da União de 19 maio de 2004, Brasília, DF, 2004a.

.(Conselho Nacional de Educação).Resolução No.1 de 17 de Junho de 2004. Institui Diretrizes curriculares nacionais para a educação das relações étnico-raciais e para o ensino de história e cultura afro-brasileira e africana. Brasília, DF, 2004b.

. (Ministério da Educação). Orientações e ações para a educação das relações étnico-raciais. Brasilia: SECAD, 2006.

. (Ministério da Educação e Cultura). Orientações e Ações para a Educação das Relações Étnico-Raciais. Brasília, DF: MEC/SECAD 2006. Disponível em: < http://portal.mec.gov. br/dmdocuments/orientacoes etnicoraciais.pdf> Acesso em: 03 set. 2013.

. (Comitê Nacional de Educação em Direitos Humanos). Plano Nacional de Educação em Direitos Humanos / Comitê Nacional de Educação em Direitos Humanos. Brasília: Secretaria Especial dos Direitos Humanos, Ministério da Educação, Ministério da Justiça, UNESCO, 2007.

CAMPBELL, Jack (Org). Construindo um futuro comum: educando para a integração na diversidade. Brasília: UNESCO, 2002.

CASTELLS, Manuel. O poder da identidade, Vol. III. São Paulo: Ed. Paz e Terra, 2005. (Coleção: A Era da Informação: Economia, Sociedade e Cultura)

CAVALLEIRO, Eliane dos Santos. Discriminação racial e pluralismo em escolas públicas da cidade de São Paulo. In: Educação anti-racista: caminhos abertos pela lei Federal 10.639/03. Secretaria de Educação Continuada, Alfabetização e Diversidade. Brasília: Ministério da Educação, Secretaria de Educação Continuada, Alfabetização e Diversidade,, 2005. (Coleção Educação para todos)

COMPARATO, Flávio Konder. A afirmação Histórica dos Direitos Humanos. São Paulo: Ed. Saraiva, 1999.

DOMINGUES, Petrônio. Movimento negro brasileiro: alguns apontamentos históricos. Tempo [online]. Niterói, v.12, n.23, 2007. p.100-122. Disponível em: $<\underline{\text { http://www.scielo.br/scielo. }}$ php?script $=$ sci arttext\&pid $=$ S1413-77042007000200007\&lng=pt\&nrm=iso. $>$ Acesso em: 03 set. 2013. 
FANON, Frantz. Pele negra, máscaras brancas. Salvador: EDUFBA, 2008.

FREIRE, Paulo. Conscientização. Rio de Janeiro: Paz e Terra, 1978.

FREYRE, Gilberto. Casa grande \& senzala. Rio de Janeiro: Schimidt, 1933.

GOMES, Nilma Lino. Diversidade Cultural, Currículo e questão racial: desafios para a prática pedagógica. In: ABRAMOWICZ, Anete, BARBOSA, Lucia Maria de Assunção; SILVEIRO, Valter Roberto. (Org.) Educação como prática da diferença. Campinas: Armazém do Ipê, 2006.

GONÇALVES, Luiz Alberto Oliveira; SILVA, Petronilha Beatriz Gonçalves. O jogo das diferenças: o multiculturalismo e seus contextos. $3^{\text {a }}$ ed. Belo Horizonte: Autêntica, 2001.

GUSMÃO, Neusa Maria Mendes de. Linguagem, cultura e alteridade: imagens do outro. $\mathrm{Ca}$ dernos de Pesquisa (Fundação Carlos Chagas). São Paulo/Campinas, v. 107, n. 0, p. 41-78, 1999.

HALL, Stuart. A identidade cultural na pós modernidade. Rio de Janeiro: DP\&A, 2005.

PELBART Peter Pál. Deleuze e a Educação. In: ABRAMOWICZ, Anete; SILVEIRO, Valter Roberto. (Org.). Afirmando Diferenças: Montando o quebra-cabeça da diversidade na escola. Campinas: Papirus, 2005. p. 09-12.

PINTO, Regina P. Movimento Negro e Educação do Negro: a ênfase na identidade. Cadernos de Pesquisa, São Paulo, n. 86, p. 25-38, ago. 1993.

PIOVESAN, Flávia. Ações Afirmativas sob a perspectiva dos direitos humanos. In: SANTOS, Sales Augusto dos. Ações Afirmativas e Combate ao Racismo nas Américas. Brasília: Ministério da Educação; Secretaria de Educação Continuada, Alfabetização e Diversidade, 2005. p. 33-44.

RICARDO, Luís F. F. Aulas assistidas? Está aberta a época de teatro. A Página da educação. Porto, Portugal, v. 17, n. 176, p. 43, mar. 2008.

ROSSATO, César; GESSER, Verônica. A experiência da branquitude diante de conflito raciais: estudos de realidades brasileiras e estadunidenses. In: CAVALLERO, Eliane dos Santos. Racismo e anti-racismo: repensando nossa escola. São Paulo: Selo Negro, 2001. p. 11-38.

SANTOS, Ivair Alves dos. Ações Afirmativas: Farol de expectativas. In: SOUZA JUNIOR, José Geraldo de. Educando para os direitos humanos: pautas pedagógicas para a cidadania na universidade. Porto Alegre: Síntese, 2004. p. 149-169.

SANTOS, Sales Augusto dos. A lei n ${ }^{\circ} 10.639 / 03$ como fruto da luta anti-racista do Movimento Negro. In: Educação anti-racista: caminhos abertos pela lei Federal 10.639/03. Brasília: Ministério da Educação, Secretaria de Educação Continuada, Alfabetização e Diversidade, 2005. p.21-38.

SILVA, Ana Célia da. A desconstrução da discriminação no livro didático. In: MUNANGA, Kabengele (Org.) Superando o racismo na escola. $2^{\mathrm{a}}$ ed. revisada. Brasília: Ministério da Educação/SECAD, 2005. 
SILVA, Claudilene. O Processo de Implementação da Lei No 10.639/03 na Rede Municipal de Ensino do Recife. In: AGUIAR, Márcia Ângela et al (Orgs.) Educação e Diversidade: Estudos e Pesquisas, v.2. Recife: Gráfica J. Luiz Vasconcelos Ed., 2009. p.9-38

SILVA, Consuelo Dores. Negro, qual é o seu nome? Belo Horizonte: Mazza, 1995.

SILVA JUNIOR, Hédio. Mulher e negra: necessidade de demandas judiciais específicas. In: BARSTED, Leila L.; Jacqueline HERMANN.(Orgs.) As mulheres e a legislação contra o racismo. Rio de Janeiro: CEPIA, 2001. p. 9-42.

SILVA, Petronilha Beatriz Gonçalves. Aprender, ensinar e relações étnico-raciais no Brasil. Educação, Porto Alegre, v.30, n³, p. 489-506, set/dez. 2007.

SILVA, Petronilha Beatriz Gonçalves; BARBOSA, Lúcia Maria de Assunção (Org.) Pensamento Negro em Educação no Brasil. São Carlos: EDUFSCar, 1997.

SILVA, Petronilha Beatriz Gonçalves et al. Práticas sociais e processos educativos: costurando retalhos de uma colcha. São Carlos, UFSCar, PPGE, Linha de Pesquisa, Práticas sociais e Processos Educativos, 2007.

SILVA, Petronilha Beatriz Gonçalves; OLIVEIRA, Evaldo Ribeiro; MORAIS, Danilo de Souza. As Leis 10.399/03 e 11.465/08 se fazem necessárias? Presente! Revista de Educação. Salvador, Ano 16 n. 4, p. 32-33, dez/2008.

SILVÉRIO, Valter Roberto. Sons negros com ruídos brancos. Racismo no Brasil. In: Racismo no Brasil. São Paulo, Peirópolis, Abong, 2002. p.89-104.

TSEBELIS, George. Atores com poder de veto: como funcionam as instituições politicas. Rio de Janeiro: Ed. FGV, 2009.

Recebido em: 30/03/2013

Revisão em: 01/09/2013

Aceite em: 08/09/2013

Flavio Santiago possui graduação em Pedagogia pela Universidade Federal de São Carlos (2010). Atualmente é aluno do Programa de Pós-graduação em Educação da Universidade de Campinas e membro do Grupo de Estudos e Pesquisas em diferenciação sociocultural - GEPEDISC/ Culturas Infantis da UNICAMP e do Núcleo de Estudos Afro-brasileiros (NEAB) UFSCar. Tem experiência na área de Educação, atuando principalmente nos seguintes temas: Educação Infantil, Educação das Relações Étnico-Raciais, Sociologia da Infância. Endereço para correspondência: Rua Dr. Mello Peixoto nº60 Centro. Ribeirão Bonito/SP, Brasil. CEP: 13580-000 E-mail: flavio.fravinho@gmail.com 
Adriana Duarte de Souza Carvalho é licenciada e bacharel em Ciências Sociais pela UNESP e mestre em Sociologia pela mesma instituição. É doutora em Ciência Política pela Universidade Federal de São Carlos (UFSCar). Desenvolve pesquisas nas áreas de instituições políticas e políticas públicas. Atualmente é professora do Centro Universitário Claretiano de Batatais, em cursos de graduação e pós-graduação. Endereço para correspondência: Rua Episcopal, 408. Núcleo Residencial Silvo Vilare. São Carlos, SP, Brasil. CEP 13560570. E-mail: adriana.dsc@hotmail.com 